\title{
Molecular epidemiological analysis of wild animal rabies isolates from India
}

Gundallhalli Bayyappa Manjunatha Reddy ${ }^{1}$, Rajendra Singh ${ }^{2}$, Karam Pal Singh ${ }^{2}$, Anil Kumar Sharma², Sobharani Vineethaㄹ ${ }^{2}$ Mani Saminathan ${ }^{2}$ and Basavaraj Sajjanar ${ }^{2}$

1. Department of Veterinary Pathology, ICAR-National Institute of Veterinary Epidemiology and Disease Informatics, Bengaluru, Karnataka, India; 2. Department of Veterinary Pathology, ICAR-Indian Veterinary Research Institute, Bareilly, Uttar Pradesh, India.

Corresponding author: Gundallhalli Bayyappa Manjunatha Reddy, e-mail: gbmpatho@gmail.com Co-authors: RS: rajendra singh5747@rediffmail.com, KPS: karam.singh@rediffmail.com, AKS: aksharmaivri@rediffmail.com, SV: gbmpatho@rediffmail.com, MS: drswamyvet@gmail.com, BS: bksvet@gmail.com Received: 27-10-2018, Accepted: 18-01-2019, Published online: 04-03-2019

doi: 10.14202/vetworld.2019.352-357 How to cite this article: Reddy GBM, Singh R, Singh KP, Sharma AK, Vineetha S, Saminathan M, Sajjanar B (2019) Molecular epidemiological analysis of wild animal rabies isolates from India, Veterinary World, 12(3): 352-357.

\begin{abstract}
Aim: This study was conducted to know the genetic variability of rabies viruses (RVs) from wild animals in India.

Materials and Methods: A total of 20 rabies suspected brain samples of wild animals from different states of India were included in the study. The samples were subjected for direct fluorescent antibody test (dFAT), reverse transcription polymerase chain reaction (RT-PCR), and quantitative reverse transcriptase real-time PCR (RT-qPCR). The phylogenetic analysis of partial nucleoprotein gene sequences was performed.
\end{abstract}

Results: Of 20 samples, 11, 10, and 12 cases were found positive by dFAT, RT-PCR, and RT-qPCR, respectively. Phylogenetic analysis showed that all Indian wild RVs isolates belonged to classical genotype 1 of Lyssavirus and were closely related to Arctic/Arctic-like single cluster indicating the possibility of a spillover of rabies among different species.

Conclusion: The results indicated the circulation of similar RVs in sylvatic and urban cycles in India. However, understanding the role of wild animals as reservoir host needs to be studied in India.

Keywords: India, nucleoprotein gene, phylogenetic analysis, rabies virus, wild animals.

\section{Introduction}

Rabies is enzootic and is a serious public health and economic problem in India. Rabies virus (RV) belongs to phylogroup I of genus Lyssavirus and family Rhabdoviridae. Of the 14 distinct species recognized within the genus Lyssavirus, the classical RV is the most prevalent and widely distributed [1]. Dog-mediated rabies account to nearly 20,000 human deaths per year in India and are considered as principal reservoir hosts followed by cats and other wild animals [2,3]. Recently, 21 cases of human rabies have been reported in Edakkad, Kannur district, Kerala, India, due to mongoose bite. This is the first report from India on a massive attack of humans by mongoose and rabies transmission [4].

The transmission of rabies from wild animals is rarely reported in endemic countries such as India $[2,3,5]$. The occurrence of dog rabies has masked the importance of wild animal rabies in India. In rabies control programs, more attention was given to dog-mediated rabies, but there is a need to monitor for possible risk of wildlife populations getting infected with rabies. The

Copyright: Reddy, et al. Open Access. This article is distributed under the terms of the Creative Commons Attribution 4.0 International License (http://creativecommons.org/licenses/by/4.0/), which permits unrestricted use, distribution, and reproduction in any medium, provided you give appropriate credit to the original author(s) and the source, provide a link to the Creative Commons license, and indicate if changes were made. The Creative Commons Public Domain Dedication waiver (http://creativecommons.org/ publicdomain/zero/1.0/) applies to the data made available in this article, unless otherwise stated. genetic characterization of urban RABV isolates from domestic and human origin has been well documented by targeting different regions of RV genome [6-8].

However, sylvatic or wild animal rabies in India is not studied extensively, and the reports are scanty $[3,9]$. Therefore, an attempt was made on limited non-random rabies suspected brain samples to understand the genetic related of wild animal RVs with other domestic animals in India.

\section{Materials and Methods}

\section{Ethical approval}

No live wild animals were used during the study. Suspected brain samples from different species of wild animals that were already dead were submitted for laboratory confirmation of rabies.

\section{Study area and rabies isolates}

Between 2007 and 2017, 20 rabies suspected brain samples from dead animals covering different species of wild animals from different states of India such as Delhi (sambar deer, Himalayan sloth bear, hyena, and mongoose), Gujarat (hyena), Karnataka (wolf and bear), Punjab (jackal), Rajasthan (hyena), and Uttar Pradesh (bear) were submitted for confirmatory rabies diagnosis (Table-1 and Figure-1). Among them, 17 brain samples were received over ice and three samples in $10 \%$ neutral buffered formalin (NBF) as a preservative. The samples were processed for direct fluorescent antibody test (dFAT), reverse 
Table-1: Sample details, diagnosis (dFAT+qRT-PCR), and GenBank accession ID of nucleotide sequences of different wild animal species from India.

\begin{tabular}{|c|c|c|c|c|c|}
\hline $\begin{array}{l}\text { Wild animal } \\
\text { species }\end{array}$ & $\begin{array}{c}\text { Number of } \\
\text { samples }\end{array}$ & Place of sample collection & State & Result & Accession number \\
\hline \multirow[t]{4}{*}{ Bear } & 4 & Tumakuru & Karnataka & + & KT381855 \\
\hline & & Delhi & Delhi & + & KX685267 \\
\hline & & Lucknow & Uttar Pradesh & + & GU371904 \\
\hline & & Pune & Maharashtra & $+^{*}$ & - \\
\hline \multirow[t]{6}{*}{ Hyena } & 6 & Alwar & Rajasthan & + & GU371899 \\
\hline & & Ahmadabad & Gujarat & + & GU371876 \\
\hline & & Delhi & Delhi & + & KX685268 \\
\hline & & Sawai Madhopur & Rajasthan & + & Could not amplify by conventional \\
\hline & & Sawai Madhopur & Rajasthan & + & PCR (+by real-time PCR) \\
\hline & & Alwar & Rajasthan & - & - \\
\hline \multirow[t]{2}{*}{ Jackal } & 2 & Ludhiana & Punjab & + & MG181948 \\
\hline & & Bhopal & $\begin{array}{l}\text { Madhya } \\
\text { Pradesh }\end{array}$ & $+^{*}$ & - \\
\hline Leopard & 1 & Bengaluru & Karnataka & - & - \\
\hline Mongoose & 1 & Delhi & Delhi & + & KX685269 \\
\hline Sambar deer & 1 & Delhi & Delhi & + & KX685270 \\
\hline \multirow[t]{3}{*}{ Wolf } & 3 & Bagalkot & Karnataka & + & KT381854 \\
\hline & & Nagpur & Maharashtra & $+^{*}$ & - \\
\hline & & Pune & Maharashtra & - & - \\
\hline Monkey & 1 & Bengaluru & Karnataka & - & - \\
\hline Civet cat & 1 & Bengaluru & Karnataka & - & - \\
\hline
\end{tabular}

*Histopathology only, dFAT=Direct fluorescent antibody test, $\mathrm{qRT}=$ Quantitative real time, $\mathrm{PCR}=$ Polymerase chain reaction

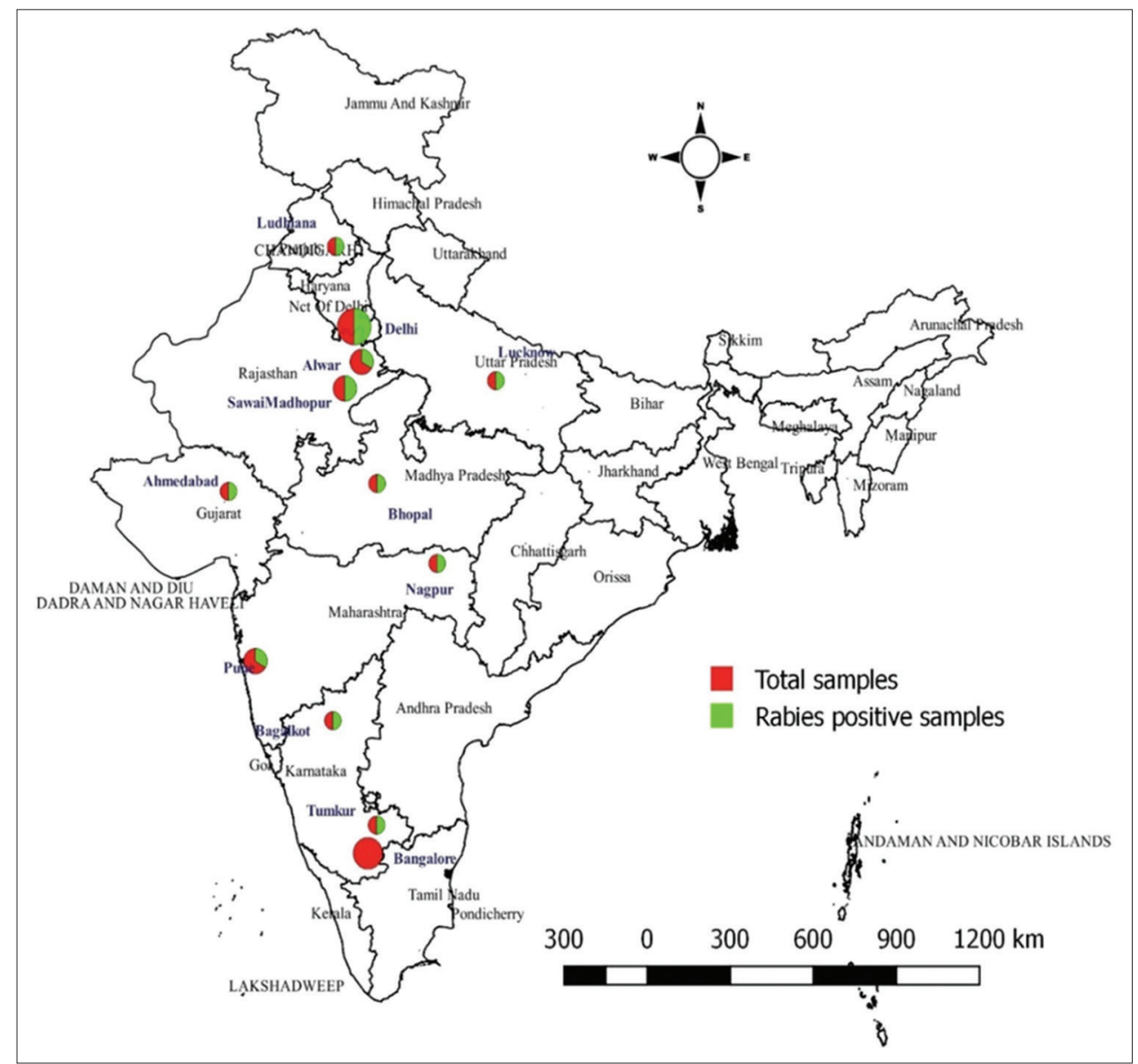

Figure-1: The map shows 20 rabies suspected sample collected locations that were surveyed in 2007-2017 (Source: The map was generated with the help of QGIS 2.18 software).

transcription-polymerase chain reaction (RT-PCR), quantitative reverse transcriptase real-time PCR (RT-qPCR), and histopathology.

\section{dFAT}

The RV antigen in the brain impression smears was detected by dFAT as recommended by the World 
Health Organization [10]. Briefly, impression smears from coronal sections of suspected brain samples were prepared and were fixed with chilled acetone. Before staining, the slides were given three washes with $1 \mathrm{X}$ phosphate-buffered saline (PBS, $\mathrm{pH}$ 7.2) for 5 min each followed by incubation with anti-rabies FITC conjugate (Millipore, USA) in a humidified dark chamber at $37^{\circ} \mathrm{C}$ for $1 \mathrm{~h}$. The slides were washed thoroughly in PBS, mounted with VECTASHIELD Antifade Mounting Medium (Vector Laboratories, CA, USA), and examined under a fluorescent microscope (Nikon, Japan). During each run, positive and negative controls were run along with test slides.

\section{Viral RNA isolation}

Viral RNA from approximately $100 \mathrm{mg}$ brain tissues was isolated using QIAamp Viral RNA Mini Kit (QIAGEN, Hilden, Germany), following the manufacturer's instructions, and quantified using spectrophotometer (ND-2000, Thermo Scientific, USA).

\section{CDNA synthesis and RT-PCR}

Complementary DNA (cDNA) was synthesized from the viral RNA by QuantiTect Reverse Transcription Kit (QIAGEN, Hilden, Germany), following the manufacturers' protocol. cDNA was prepared from approximately $1 \mu \mathrm{g}$ of viral RNA by incubating $20 \mu \mathrm{l}$ reaction mixture at $42^{\circ} \mathrm{C}$ for $30 \mathrm{~min}$ followed by heat inactivation at $95^{\circ} \mathrm{C}$ for $3 \mathrm{~min}$. RT-PCR was performed using $\mathrm{N}$ gene-specific primers [7] in $50 \mu 1$ reaction mixture containing Platinum Pfx DNA Polymerase $(2.5 \mathrm{U} / \mu \mathrm{l})$ using gradient thermocycler (Mastercycler Personal, Eppendorf, Germany). The PCR products were electrophoresed, and gel-containing specific amplicons were sliced and were subjected for gel extraction using QIAquick Gel Extraction Kit (QIAGEN, Hilden, Germany).

\section{Quantitative real-time (qRT)-PCR}

Irrespective of dFAT and RT-PCR results, all the samples were subjected forSYBR green dye-based RT-qPCR using specific primers [7] in MX3000P quantitative PCR System (Stratagene, USA). A melting curve analysis was performed to know the specificity of RT-qPCR.

\section{Histopathology}

Three 10\% NBF preserved brain tissues were processed for histopathological examination. Tissue samples of 1-2 mm thickness were dehydrated in graded alcohol and cleared in xylene and embedded in paraffin blocks. The 4-5 $\mu$ thick sections were taken with rotator microtome on clean grease-free slides and subjected for hematoxylin and eosin staining. The brain tissue sections were examined under a light microscope for the presence of characteristic eosinophilic intracytoplasmic Negri bodies.

\section{Nucleotide sequencing and phylogenetic analysis}

The paired-end Sanger's dideoxy sequencing (Xcelris Genomics, India) was performed with forward and reverse $\mathrm{N}$ gene primers. The edited sequences were submitted to GenBank and were assigned accession numbers (Table-1). The sequence alignment was performed in muscle program, and phylogenetic tree was derived at 1000 bootstraps by maximum likelihood method based on the Tamura-Nei model in MEGA7.0 [11]. Published N gene sequences from India and rest of the world were also included for phylogenetic analysis (supplementary file).

\section{Results}

\section{Detection of RV}

Impression smears from rabies-positive brain tissues showed characteristic diffuse apple green fluorescent signals of RABV antigen with varying degrees in the cytoplasm of the neurons by dFAT. Of 20 rabies suspected samples, 11 samples were found positive with dFAT. The RNA was isolated from 17 brain samples, which were received over ice. However, RNA could not be isolated from three formalin-fixed samples. Of 17 samples, conventional RT-PCR amplified the $\mathrm{N}$ gene of $\mathrm{RV}$ with an expected product size of 806 bp in 10 samples, and 12 samples were positive by RT-qPCR without any non-specific reactions with specific melting temperature $\left(82.24-83.11^{\circ} \mathrm{C}\right)$ (Table-1).

\section{Histopathology}

Three formalin-fixed brain samples of wild animals were positive for rabies by revealing characteristic round-to-oval, eosinophilic intracytoplasmic Negri bodies in the pyramidal cells of the hippocampus and cerebellar Purkinje cells. Other histopathological changes were neuronal necrosis, satellitosis, gliosis, neuronophagia, congestion, edema, perivascular cuffing, and meningitis.

\section{Phylogenetic analysis}

Of 12 nucleic acid-positive rabies samples (qRT-PCR), in 10 samples, we could get desired N gene nucleotide sequences and got accession numbers (Table-1). These 10 partial $\mathrm{N}$ gene nucleotide sequences were compared with published sequences of RV from different species and geographical regions of India. The phylogenetic tree revealed two distinct clades: Clade-1/Group-1 (Gr-1) or Arctic-like lineage and clade-2/Group-2 (Gr-2) or subcontinental lineage $\mathrm{RV}$ among the Indian RV isolates (Figure-2). The Gr-2 lineage isolates were restricted to the southern part of India, whereas Gr-1 lineage isolates were spread throughout the Indian subcontinent. Among the Gr-1, three distinct subgroups were noticed, namely Gr-1A, Gr-1B, and Gr-1C. All the RV isolates from wild animals belonged to Gr-1 RV of Indian origin (Gr-1 A and Gr-1B), which are closely related to Arctic/Arctic-like single cluster and contained RV isolates from different herbivores and carnivore animals and human origin within India (Figure-2). All the wild animal RV isolates were having similar topology and grouped under Arctic/Arctic-like RV viruses (Figure-3). The wild RV isolates did not demonstrate any pattern for their host species of isolation, and even there was no pattern for geographical origin. The $\mathrm{N}$ gene identity of Indian 


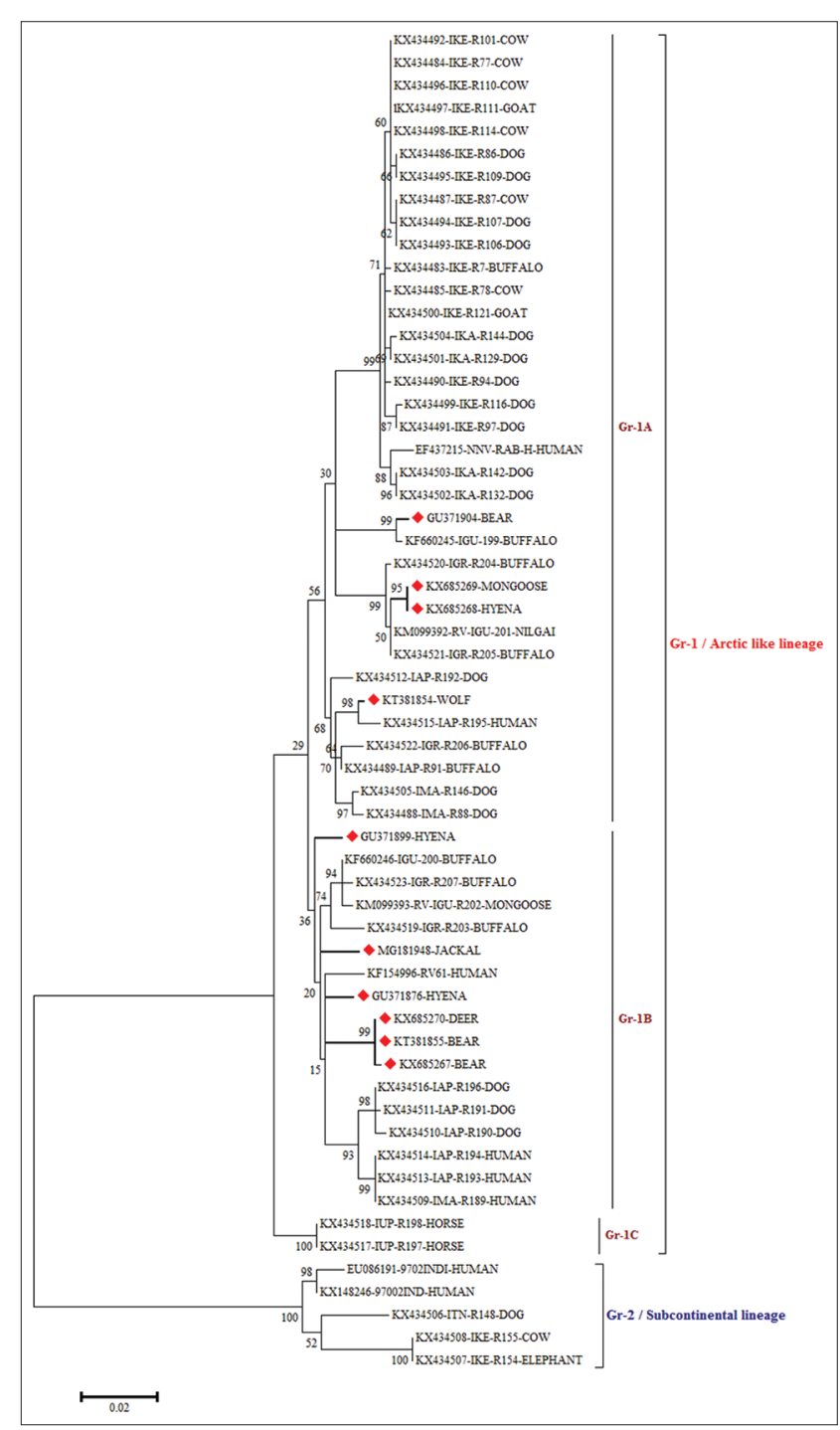

Figure-2: Maximum likelihood tree generated by $690 \mathrm{bp}$ of nucleoprotein gene sequences showing the genetic relationship of the wild animal rabies virus isolates with other Indian rabies virus isolates. The percentage of bootstrap values given to the left of the main branch. Isolates for which the partial $\mathrm{N}$ gene sequence was obtained in this study are indicated by a triangle (diamond red color).

wild RV isolates varied from $96 \%$ to $100 \%$, while with Pasteur virus (PV) strain varied from $88.6 \%$ to $89.6 \%$. The nucleotide frequencies for wild animal RV isolates were $27.64 \%$ (A), $26.18 \%(\mathrm{~T}), 25.62 \%$ (G), and $20.56 \%(\mathrm{C})$.

The $\mathrm{N}$ gene-derived amino acid sequence identity of wild animal RV isolates varied from $99.6 \%$ to $100 \%$. The amino acid sequences varied at position 151 (A-G), 185 (K-R), 192 (A-T), 228 (T-A), and 231 (I-M) as compared to PV strain, whereas the majority of wild animal Indian RV isolates (WINR) showed high identity except at 185 (K-R) in WINR-5 and at 192 (T-A) in WINR-3, WINR-4, and WINR-6 compared to PV strain.

\section{Discussion}

Till date, few studies conducted on these aspects were done with either single or two samples to best of

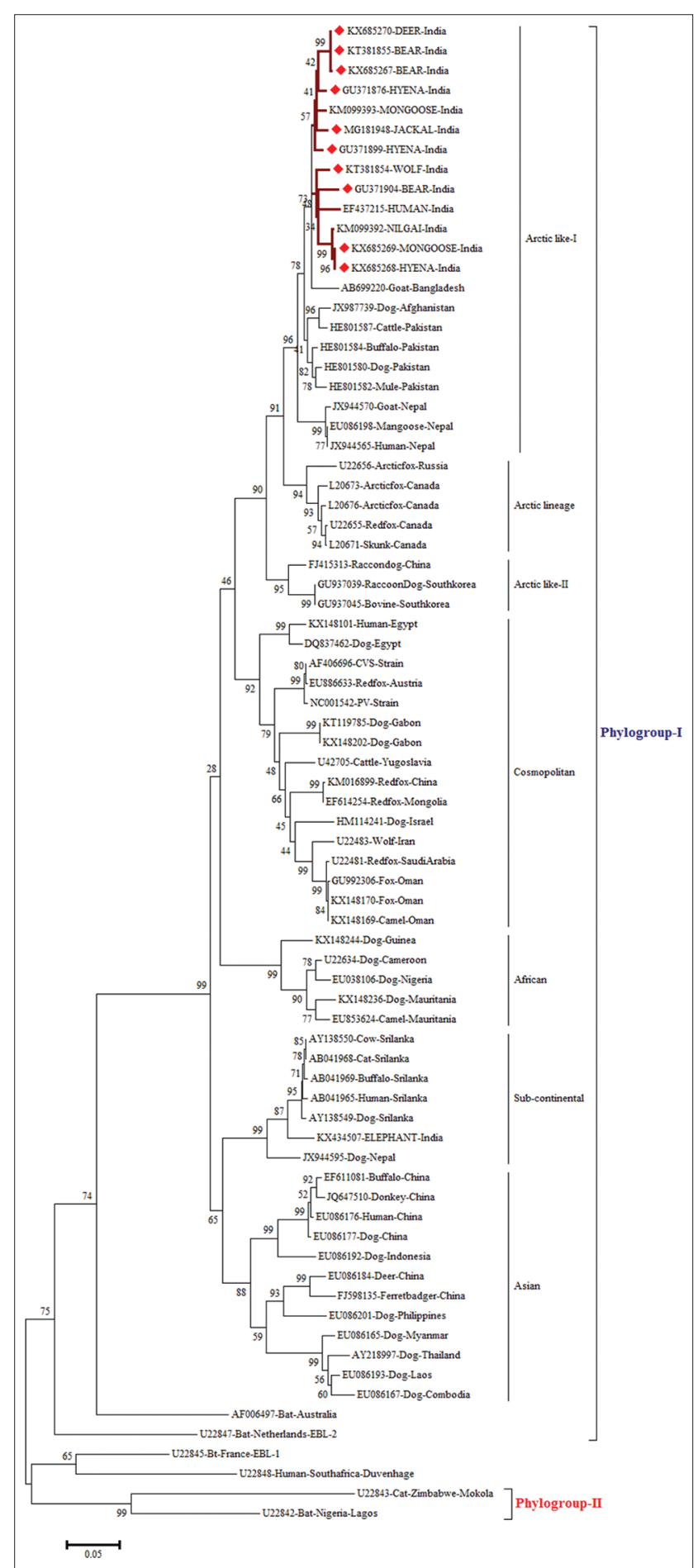

Figure-3: Maximum likelihood tree generated by 690 bp of nucleoprotein gene sequences showing the genetic relationship of the Indian rabies virus isolates with global RABV isolated. The percentage of bootstrap values given to the left of the main branch. Isolates for which the partial $\mathrm{N}$ gene sequence was obtained in this study are indicated by a triangle (diamond red color).

our knowledge. The samples submitted to laboratory for confirmatory diagnosis over a period of 10 years were subjected for dFAT at first, and 12 samples were positive. Two samples were missed with dFAT compared to qRT-PCR which is attributed to the condition of samples received at the time of diagnosis as it has been reported that both environmental and 
non-environmental factors alter the sensitivity of dFAT [12]; especially, it is true for a country like India which is tropical in nature and less accessibility to rabies diagnostic laboratories. Even the conventional RT-PCR also showed low sensitivity than qRT-PCR which might be attributed to decomposition of samples wherein the RNases degrade the genome into smaller segments [13].

Further, degraded and lower number of nucleic acid copies might be resulted in two missed cases by RT-PCR, but which were turned-out to be positive by qRT-PCR. Three formalin-fixed brain samples of wild animals were positive for rabies by revealing characteristic round-to-oval, eosinophilic intracytoplasmic Negri bodies in the pyramidal cells of the hippocampus and cerebellar Purkinje cells. Other histopathological changes observed were neuronal necrosis, satellitosis, gliosis, neuronophagia, congestion, edema, perivascular cuffing, and meningitis [1].

The $\mathrm{N}$ gene-based phylogenetic tree showed two clades/groups, with Gr-2 lineage isolates which are restricted to the southern part of India, and on the contrary, Gr-1 lineage RV isolates were spread throughout Indian subcontinent. The phylogenetic analyses also showed that all RV isolates from wild animals were falling under the urban group of RV isolates from the rest of India and are closely related to Arctic/Arcticlike single cluster (Figure-3) which is an account of conservation pattern of nucleotide sequences in $\mathrm{N}$ gene. Among the RV strains, $\mathrm{N}$ gene is frequently used as a diagnostic and molecular marker for epidemiological analysis of Lyssavirus distribution regionally and globally compared to other genes [14]. Even though the isolates were from different geographical regions of country, they formed a single cluster which is nearer to Arctic lineage of RVs that circulate throughout the Arctic countries and are considered as phylogenetic ancestors of RV isolates in India also known as Arctic/ Arctic-like lineage. The Arctic-like lineage accounts for the type circulating throughout India. Arctic RV has been shown to adapt to different hosts including fruit- and insect-eating bats and Arctic fox [15]. Our findings are in contrast to many reports of geographically restricted distribution of urban and circulation of two distinct lineages (Arctic and Asian) of RV in India $[7,8]$. In India, even though dog is the main reservoir of rabies transmission, the genetic similarity of the isolates from the present study reveals the possible role of wildlife in harboring RV cannot be ruled out, an issue that needs urgent attention. The unrestricted movement of domestic animals and no physical barrier between wild and domestic animals interface in India. Under these circumstances, there is a requirement of further detailed investigation of wildlife rabies cases, especially at wild-domestic-human interface and also due to a rise in wild animal transmitted rabies cases $[1,2]$. The close identity of RV from India with Afghanistan followed by Pakistan, Nepal, Russia, and Canada (Arctic strain) is in accordance with previous findings that the viruses from the South Asian countries and Canada have a common ancestry $[7,9,15]$. From this study, it can be inferred that, based on partial $\mathrm{N}$ gene, wild animal RV isolates are almost similar in their genetic epidemiology suggesting high endemic stability of RV in India and possibility of spillover [16]. The current study supports the spillover of long-term canine-mediated rabies enzootics into wild terrestrial carnivores complicating the control efforts and increasing the risk of exposure to humans [17]. The amino acid pattern derived from the partial nucleotide sequences of $\mathrm{N}$ gene did not indicate any signature substitutions with respect to the geographical origin and host species. However, previous studies on domestic animal rabies featured clustering of virus isolates according to geographical origin irrespective of host species $[7,18]$.

\section{Conclusion}

The partial $\mathrm{N}$ gene sequence analysis showed that genetically similar RV of phylogroup I is circulating both in wild and domestic animals highlighting the important role played by wild animals in the transmission and maintenance of rabies in India. Hence, there is a need for further detailed studies targeting other genes of virus or whole genome approach for elucidating the phylodynamics of rabies in wild animals. Further, understanding the epidemiology of rabies at human-wild-domestic animal interface will help in better design and implementation of rabies prevention and control in the future.

\section{Authors' Contributions}

Conceptualization: GBMR, RS, and KPS; Data curation and formal analysis: GBMR, SV, and BS; Funding acquisition: GBMR; Investigation: GBMR, RS, KPS, and AKS; Project administration: GBMR, RS, and KPS; Resources: GBMR and RS; Software: GBMR, SV, BS, and MS; Supervision: GBMR and RS; Validation: GBMR, RS, and KPS; Writing - original draft: MS, BS, and SV; Writing - review and editing: GBMR and MS. All authors read and approved the final manuscript.

\section{Acknowledgments}

The authors are thankful to the Directors of ICAR-NIVEDI and ICAR-IVRI for providing necessary facilities and to the Science and Engineering Research Board, Department of Science and Technology, Government of India (Grant no. SR/FT/ LS-93/2012).

\section{Competing Interests}

The authors declare that they have no competing interests.

\section{Publisher's Note}

Veterinary World remains neutral with regard to jurisdictional claims in published map and institutional affiliation. 


\section{References}

1. Singh, R., Singh, K.P., Cherian, S., Saminathan, M., Kapoor, S., Reddy, G.B.M., Panda, S. and Dhama, K. (2017) Rabies-epidemiology, pathogenesis, public health concerns and advances in diagnosis and control: A comprehensive review. Vet. Q., 37(1): 212-251.

2. Madhusudana, S.N., Mani, R., Ashwin, Y.B. and Desai, A. (2013) Rabid fox bites and human rabies in a village community in Southern India: Epidemiological and laboratory investigations, management and follow-up. Vector Borne Zoonotic Dis., 13(5): 324-329.

3. Suja, M.S., Mahadevan, A., Sundaram, C., Mani, J., Sagar, B.C., Hemachudha, T., Wacharapluesadee, S., Madhusudana, S.N. and Shankar, S.K. (2004) Rabies encephalitis following fox bite--histological and immunohistochemical evaluation of lesions caused by virus. Clin. Neuropathol., 23(6): 271-276.

4. Jayson, E.A. and Govind, S.K. (2014) Mongoose rabies in Kannur, Kerala, India. J. Bombay Nat. Hist., 111(2): 125-126.

5. Reddy, G.B.M., Krishnappa, S., Vinayagamurthy, B., Singh, R., Singh, K.P., Saminathan, M., Sajjanar, B. and Rahman H. (2018) Molecular epidemiology of rabies virus circulating in domestic animals in India. Virus disease, 29(3): 362-368.

6. Cherian, S., Singh, R., Singh, K.P., Reddy, G.B.M., Anjaneya, Kumar, G.V.P., Sumithra, T.G. and Singh, R.P. (2015) Phylogenetic analysis of Indian rabies virus isolates targeting the complete glycoprotein gene. Infect. Genet. Evol., 36(12): 333-338.

7. Reddy, G.B., Singh, R., Singh, R.P., Singh, K.P., Gupta, P.K., Mahadevan, A., Shankar, S.K., Ramakrishnan, M.A. and Verma, R. (2011) Molecular characterization of Indian rabies virus isolates by partial sequencing of nucleoprotein $(\mathrm{N})$ and phosphoprotein $(\mathrm{P})$ genes. Virus Genes, 43(1): 13-17.

8. Reddy, R.V., Subramanian, B.M., Surendra, K.S., Babu, R.P., Rana, S.K., Manjari, K.S. and Srinivasan, V.A. (2014) Rabies virus isolates of India-simultaneous existence of two distinct evolutionary lineages. Infect. Genet. Evol., 27(11): 163-172.

9. Reddy, R.V.C., Mukherjee, F., Rana, S.K., Kanani, A.,
Surendra, K.S.N., Subramanian, M., Sharma, G.K. and Villupanoor, S.A. (2015) Rabies virus infection in domestic buffaloes and wild animals in India. $J$. Adv. Vet. Res., 5(2): 68-83.

10. Meslin, M., Koprowski, H. and Kaplan, M.M. (1996) Laboratory Techniques in Rabies. $4^{\text {th }}$ ed. WHO, Geneva.

11. Kumar, S., Stecher, G. and Tamura, K. (2016) MEGA7: Molecular evolutionary genetics analysis version 7.0 for bigger datasets. Mol. Biol. Evol., 33(7): 1870-1874.

12. Duong, V., Tarantola, A., Ong, S., Mey, C., Choeung, R., Ly, S., Bourhy, H., Dussart, P. and Buchy, P. (2016) Laboratory diagnostics in dog-mediated rabies: An overview of performance and a proposed strategy for various settings. Int. J. Infect. Dis., 46(5): 107-114.

13. David, D., Yakobson, B., Rotenberg, D., Dveres, N., Davidson, I. and Stram, Y. (2002) Rabies virus detection by RT-PCR in decomposed naturally infected brains. Vet. Microbiol., 87(2): 111-118.

14. Marston, D.A., McElhinney, L.M., Johnson, N., Müller, T., Conzelmann, K.K., Tordo, N. and Fooks, A.R. (2007) Comparative analysis of the full genome sequence of European bat lyssavirus Type 1 and Type 2 with other Lyssaviruses and evidence for a conserved transcription termination and polyadenylation motif in the G-L 3' non-translated region. J. Gen. Virol., 88(Pt 4): 1302-1314.

15. Nadin-Davis, S.A., Sheen, M. and Wandeler, A.I. (2011) Recent emergence of the Arctic rabies virus lineage. Virus Res., 163(1): 352-362.

16. Pant, G.R., Lavenir, R., Wong, F.Y.K., Certoma, A., Larrous, F., Bhatta, D.R., Bourhy, H., Stevens, V. and Dacheux, L. (2013) Recent emergence and spread of an arctic-related phylogenetic lineage of rabies virus in Nepal. PLoS Negl. Trop. Dis., 7(11): e2560.

17. Velasco-Villa, A., Mauldin, M.R., Shi, M., Escobar, L.E., Gallardo-Romero, N.F., Damon, I., Olson, V.A., Streicker, D.G. and Emerson, G. (2017) The history of rabies in the Western Hemisphere. Antiviral Res., 146(10): 221-232.

18. Nagarajan, T., Nagendrakumar, S.B., Mohanasubramanian, B., Rajalakshmi, S., Hanumantha, N.R., Ramya, R., Thiagarajan,D. and Srinivasan, V.A. (2009) Phylogenetic analysis of nucleoprotein gene of dog rabies virus isolates from Southern India. Infect. Genet. Evol., 9(5): 976-982. 